\title{
Rancang Bangun Sistem Informasi Monitoring Pembayaran Angsuran Nasabah Bank Mandiri
}

\author{
${ }^{1}$ Andri Cahyo Purnomo, ${ }^{2}$ Sri Wahyuni, ${ }^{3}$ Andi Aruan \\ 1,2,3 Program Studi Sistem Informasi Universitas Raharja \\ Email : ${ }^{1}$ andricahyo@ raharja.info, ${ }^{2}$ sri.wahyuni@ raharja.info, ${ }^{3}$ Andi.aruan@ raharja.info
}

\begin{abstract}
Abstrak
Komputer adalah perangkat elektronik untuk memproses data yang digunakan oleh perbankan, pemerintah, dan lembaga swasta lainnya. Penggunaan komputer ini harus sesuai dengan kebutuhan organisasi yang menggunakannya, baik perangkat lunak maupun perangkat keras agar komputer dapat digunakan dengan sebaik mungkin. Bank Mandiri merupakan bank BUMN yang bergerak di bidang pelayanan jasa, tentunya ingin memberikan pelayanan yang terbaik bagi para nasabahnya. Dalam memberikan informasi mengenai angsuran di Bank Mandiri Unit Cikupa Niaga Mas 2 (CNM 2), saat ini sudah memiliki sistem yang terkomputerisasi dan berjalan dengan baik, namun hanya pegawai bank independen yang dapat menggunakan sistem tersebut, sedangkan debitur masih menggunakan sistem manual. menggunakan kertas HVS sebagai media informasi. Dibutuhkan sistem yang dapat memberikan informasi mengenai angsuran debitur secara cepat dan akurat. Penelitian ini tertarik untuk membahas tentang sistem informasi data angsuran nasabah Bank Mandiri Cikupa Niaga Mas 2 (CNM 2) yang bertujuan untuk mengoptimalkan penyediaan layanan informasi yang lebih baik bagi nasabah Bank Mandiri Cikupa Niaga mas 2 (CNM 2). Dalam penelitian ini, menggunakan analisis metode pieces, maka penulis dapat dengan mudah mengidentifikasi kelemahan-kelemahan yang ada pada sistem lama yang menghasilkan rekomendasi dalam perbaikan-perbaikan sistem berdasarkan indicator Performance, Information, Economic, Control, Efficiency, dan Service, kemudian untuk mmebuat rancangan sistem barunya, peneliti menggunakan pemodelan yang berorientasi dengan objek yaitu UML (Unified Modeling Language) yang merupakan tools yang tepat untuk digunakan dalam menggambarkan rancangan sustem yang akan dubuat sesuai kebutuhan user. Diharapkan dengan adanya sistem angsuran nasabah Bank Mandiri dapat semakin memudahkan nasabah untuk mengetahui tentang cicilan yang sedang berjalan.
\end{abstract}

Kata Kunci : Sistem, Informasi, Angsuran, Nasabah

\begin{abstract}
Computers are electronic devices for processing data used by banks, government and other private institutions. The use of this computer must be in accordance with the needs of the organization that uses it, both software and hardware so that the computer can be used as well as possible. Bank Mandiri is a state-owned bank engaged in services, of course, wants to provide the best service for its customers. In providing information about installments at Bank Mandiri Unit Cikupa Niaga Mas 2 (CNM 2), currently it has a computerized system and is running well, but only independent bank employees can use the system, while debtors still use the manual system. using HVS paper as an information medium. A system that can provide information about debtor installments quickly and accurately is needed. This study is interested in discussing the installment data information system for Bank Mandiri Cikupa Niaga Mas 2 (CNM 2) customers which aims to optimize the provision of better information services for customers of Bank Mandiri Cikupa Niaga mas 2 (CNM 2). In this study, using the analysis of the pieces method, the authors can easily identify the weaknesses that exist in the old system which results in recommendations for system improvements based on indicators of Performance, Information, Economic, Control, Efficiency, and Service, then to make a design. In the new system, researchers use object-oriented modeling, namely UML (Unified Modeling Language) which is the right tool to use in describing the design of the system that will be loaded according to
\end{abstract}


user needs. It is hoped that the Bank Mandiri customer installment system will make it easier for customers to find out about the ongoing installments.

Keywords: System, Information, Installment, Customer

\section{Pendahuluan}

Bank Mandiri adalah bank yang mengoperasikan sistem komputer dalam kegiatan pelayanan perbankannya. Banyak program layanan yang diberikan kepada nasabah, salah satunya adalah kegiatan di bidang layanan informasi angsuran kredit. Pada layanan informasi angsuran di Bank Mandiri Unit Cikupa Niaga Mas 2, saat ini sebenarnya sudah memiliki sistem yang terkomputerisasi dan berjalan dengan baik, namun hanya pegawai bank independen yang dapat menggunakan sistem tersebut, sedangkan debitur Bank Mandiri Unit Cikupa Niaga Mas 2 masih menggunakan sistem manual dengan menggunakan kertas HVS sebagai media informasi. Apabila debitur atau nasabah ingin mengetahui berapa bulan sisa cicilan atau cicilan sudah berjalan, debitur harus mencari kertas HVS yang diberikan dari Bank Mandiri pada saat perjanjian kredit dibuat, hal ini sering menjadi masalah. Karena pada dasarnya penggunaan kertas HVS rawan terjadi kerugian, kerusakan dan kesalahan dalam menghitung sisa cicilan. Pada prinsipnya, Bank Mandiri senantiasa berupaya memberikan layanan terbaik sesuai kebutuhan, termasuk layanan informasi angsuran bagi nasabah Bank Mandiri Unit Cikupa Niaga Mas 2. Setiap bulannya nasabah Bank Mandiri Unit Cikupa Niaga Mas 2 selalu meningkat. Sehingga dibutuhkan sistem yang mampu menyediakan atau memberikan informasi yang baik bagi nasabah Bank Mandiri, Cikupa Niaga Mas Unit 2. Menyadari pentingnya inovasi informasi dalam pelayanan yang baik dan memudahkan nasabah dalam memperoleh informasi angsuran kredit, berdasarkan Permasalahan diatas mendorong peneliti untuk membuat suatu sistem informasi monitoring Pembayaran Angsuran bagi nasabah Bank Mandiri khususnya Unit Cikupa Niaga Mas 2, berbasis website dengan tujuan membantu dan mempermudah pekerjaan dalam hal pelayanan kepada nasabah.

\section{TINJAUAN PUSTAKA}

Rachman [1], "Aplikasi Pembayaran dan Perizinan Santri Ponpes Assalafi Al Fithrah Surabaya Berbasis Web". Menghasilkan perancangan yang telah dilakukan adalah suatu sistem dalam pengelolaan data pembayaran dan perizinan berbasis web yang dapat dilaksanakan secara fleksibel, efisien dan efektif baik dalam waktu maupun tenaga. Antarmuka aplikasi pembayaran syariah ini, bahasa pemrograman yang digunakan PHP sedangkan MySQL sebagai database untuk menyimpan.

Kurniawan [2], "Rancang Bangun Aplikasi Pembayaran Cicilan Kredit Berbagai Toko Menggunakan Dompet Digital OVO". Kelebihan dari sistem ini yaitu toko dapat melakukan registrasi dan mempermudah pelanggannya sehingga tidak perlu repot datang ke toko untuk membayar cicilan kredit, hal ini dikarenakan aplikasi ini menggunakan layanan digital dompet OVO sebagai media atau alat tukar pembayaran. dalam membayar cicilan kredit, sehingga pelanggan dapat membayar tagihan dimanapun dan kapanpun hal ini memberikan solusi atas permasalahan yang ada, Aplikasi ini sangat bermanfaat dan membantu pengguna baik dari pelanggan maupun pemilik toko.

Alfeno, dkk [3], "Perancangan Antar Muka Aplikasi Monitoring Pembayaran Angsuran Kendaraan Bermotor Berbasis Android Pada PT Bentara Sinergies Multifinance". Tujuan dari penelitian ini adalah memiliki sistem yang mampu memberikan kemudahan khususnya bagi kolektor dan konsumen serta memberikan informasi dengan cepat dan meminimalkan waktu yang terbuang percuma. observasi, wawancara, studi pustaka, analisis, perencanaan, desain dan evaluasi prototyping adalah metode yang digunakan dalam penelitian ini. Penelitian Ini dikembangkan menjadi sebuah sistem pembayaran berbasis mobile Android yang memudahkan para kolektor untuk memonitoring konsumen yang terlambat membayar angsuran bulanan. 


\section{Metode Penelitian}

Pada metode peneltiian ini peneliti menggunakan metode analisis pieces (Performance, Information, Economy, Control, Eficiency, dan Service).[4] Sebagai analisis yang digunakan untuk sampai ke inti masalah yang lebih spesifik.

Sedangkan untuk metode perancangan yang peneliti gunakan dalam penelitian ini adalah dengan pembuatan diagram UML (Unified Modeling Language) dan ER-Diagram. Adapun bahasa pemrograman menggunakan PHP (Hypertext Preprosesor) untuk kebutuhan perangkat lunak dan MySQL sebagai database.

\section{Hasil dan Pembahasan}

Tabel 1 Analisis pieces sisitem yang berjalan

\begin{tabular}{|c|c|}
\hline Komponen Analisa & Kelemahan Sistem yang Berjalan \\
\hline Kinerja (Performance) & $\begin{array}{l}\text { Pengolahan data pembayaran debitur } \\
\text { masih dilakukan secara manual } \\
\text { dengan menggunakan kertas HVS, } \\
\text { sehingga perlu adanya perubahan } \\
\text { dengan menggunakan sistem agar } \\
\text { mempermudah kinerja petugas dalam } \\
\text { memberikan informasi mengenai } \\
\text { angsuran debitur. }\end{array}$ \\
\hline Informasi (Information) & $\begin{array}{l}\text { Informasi hanya bisa didapat dari } \\
\text { selembar kertas daftar angsuran } \\
\text { nasabah sehingga masih terjadi } \\
\text { kesalahan dan kendala serta } \\
\text { keterlambatan waktu saat pelaporan } \\
\text { penginformasian angsuran nasabah } \\
\end{array}$ \\
\hline Ekonomi (Economy) & $\begin{array}{l}\text { Penggunaan kertas dapat beberapa } \\
\text { kali dicetak karena terdapat } \\
\text { kekurangan atau kesalahan didalam } \\
\text { pembuatan data angsuran nasabah } \\
\text { dan laporan pembayaran nasabah } \\
\text { karena melakukan pencatatan pada } \\
\text { form dan pada berkas lainnya } \\
\text { ehingga terdapat pemborosan } \\
\text { sedangkan debitur sering pergi ke } \\
\text { bank lebih dari satu kali yang } \\
\text { berdampak pada transport yang } \\
\text { dikeluarkan debitur }\end{array}$ \\
\hline Kontrol (Controling) & $\begin{array}{l}\text { Dalam pembuatan laporan data } \\
\text { angsuran, setiap nasabah masih } \\
\text { dikontrol oleh Mandiri Micro } \\
\text { Manager sehingga tidak ada yang } \\
\text { terlewat dalam proses pelaporan.. }\end{array}$ \\
\hline Efisien (Eficiency) & $\begin{array}{l}\text { Sumber daya lebih banyak digunakan } \\
\text { karena masih melakukan } \\
\text { pendokumentasian manual yang } \\
\text { membuang-buang uang, waktu, } \\
\text { tenaga dan peralatan, apalagi jika }\end{array}$ \\
\hline
\end{tabular}




\begin{tabular}{|l|l|}
\hline & $\begin{array}{l}\text { terjadi kesalahan dalam pelaporan } \\
\text { angsuran. }\end{array}$ \\
\hline Pelayanan (Service) & $\begin{array}{l}\text { Dalam segi pelayanan untuk debitur } \\
\text { dirasa sudah baik tapi untuk proses } \\
\text { pelayanan system saat ini belum } \\
\text { mempermudah karyawan bank } \\
\text { mandiri karena masih terjadi kedala } \\
\text { dalam system angsuran mandiri } \\
\text { sehingga menghambat proses } \\
\text { pengolahan data laporan pembayaran } \\
\text { angsuran nasabah. }\end{array}$ \\
\hline
\end{tabular}

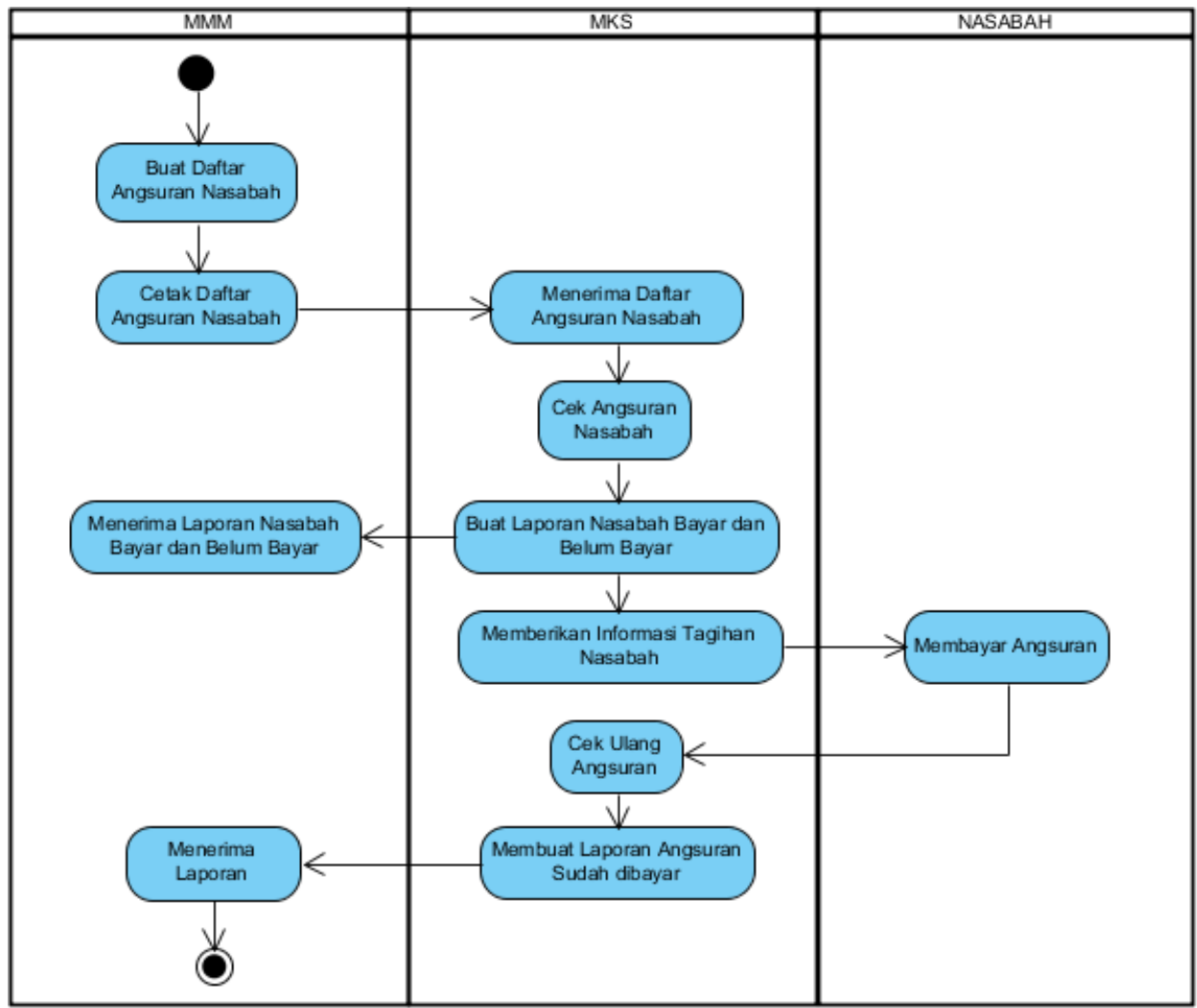

Gambar 1 Activity Diagram pengolahan data Angsuran Nasabah

Prosedur proses pegolahan data pembayaran angsuran nasabah yang sedang berjalan di Bank Mandiri Cikupa Niaga Mas 2 adalah sebagai berikut:

1. MMM (Mandiri Micro Manager) membuat daftar angsuran nasabah kemudian mencetak daftar angsuran nasabah yang telah dibuat.

2. MKS (Mandiri Kredit Sales) menerima dan mengecek daftar angsusran nasabah yang telah dibuat oleh MMM, setelah dirasa sudah benar MKS membuat laporan nasabah bayar dan belum bayar untuk dilaporakna kembali kepada MMM sebelum memberikan informasi tagihan kepada nasabah.

3. Nasabah menerima informasi tagihan dari MKS (Mandiri Kredit Sales) sebelum melakukan pembayaran.

4. MKS (Mandiri Kredit Sales) mengecek ulang apakah nasabah sudah melakukan pembayaran atau belum setelah informasi tagihan yang diberikan. Jika nasabah sudah bayar makan MKS akan membuat laporan pembayaran untuk nasabah yang sudah bayar yang akan diberikan kepada MMM (Mandiri Micro Manager). 


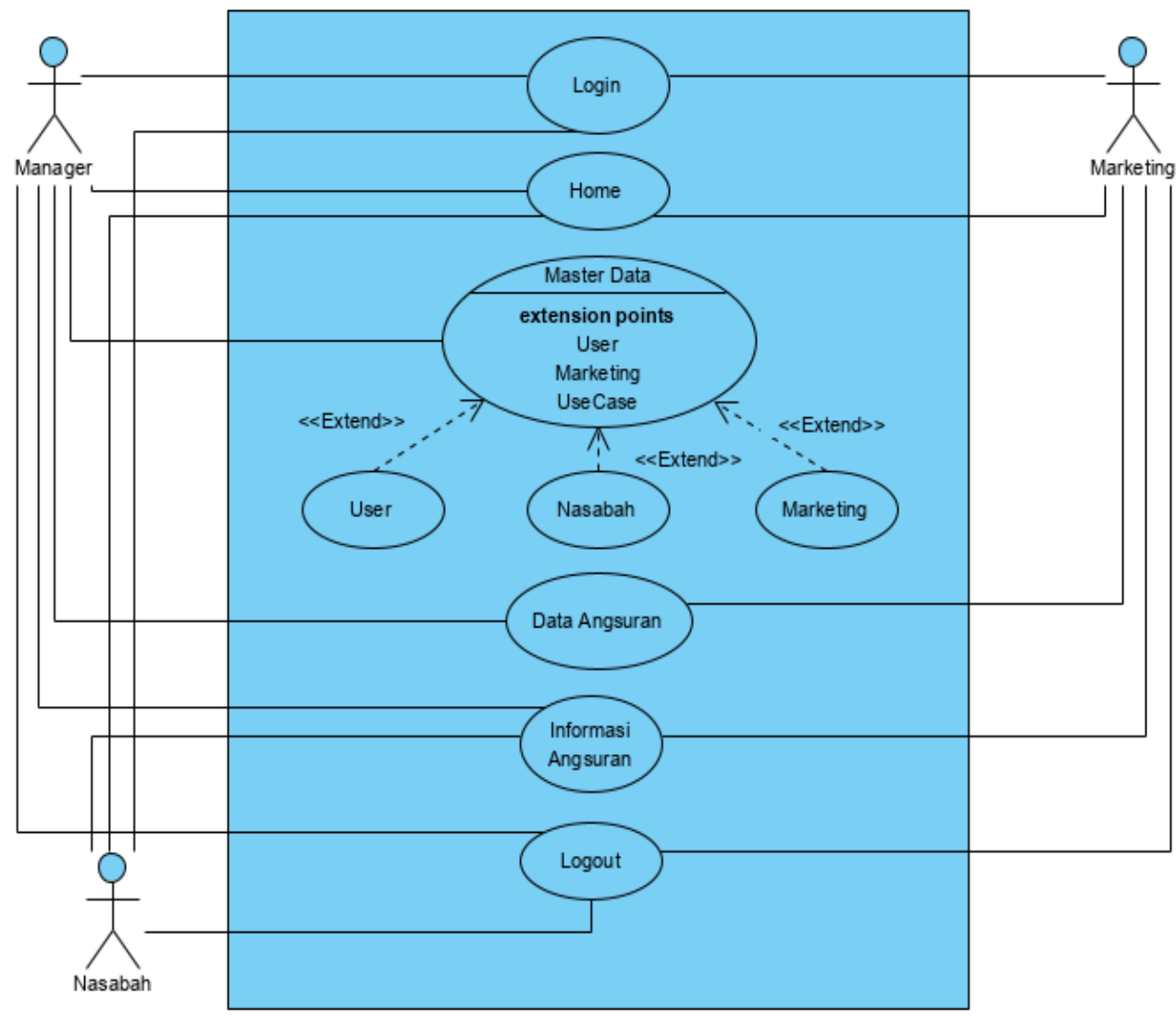

Gambar 2 Use Case Diagram Sistem Yang Diusulkan

Prosedur proses pegolahan data pembayaran angsuran nasabah yang akan diusulkan di Bank Mandiri Cikupa Niaga Mas 2 adalah sebagai berikut:

1. MMM (Mandiri Micro Manager) melakukan pengecekan data nasabah, melakukan pengecekan laporan angsuran nasabah.

2. MKS (Mandiri Kredit Sales) melakukan pengecekan data nasabah, melakukan pengecekan informasi angsuran nasabah, melakukan update data nasabah, membuat laporang angsuran nasabah.

3. Nasabah Melakukan pengecekan informasi angsuran dan melakukan pembayaran angsuran setelah mengetahui total tagihan.

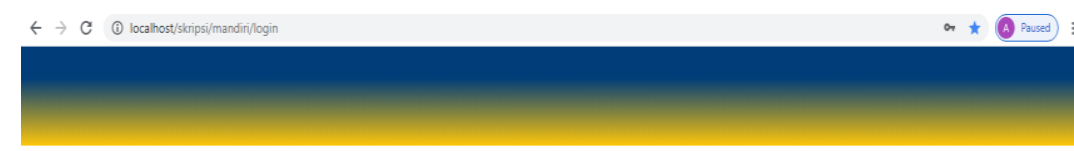

\section{mandırı}

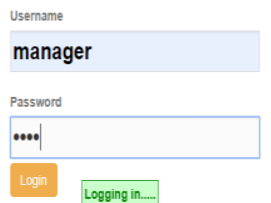


Gambar 3 halaman login

Gambar 3 merupakan halaman menu login yang diisi oleh pengguna untuk diakses ketika akan masuk ke dalam sistem

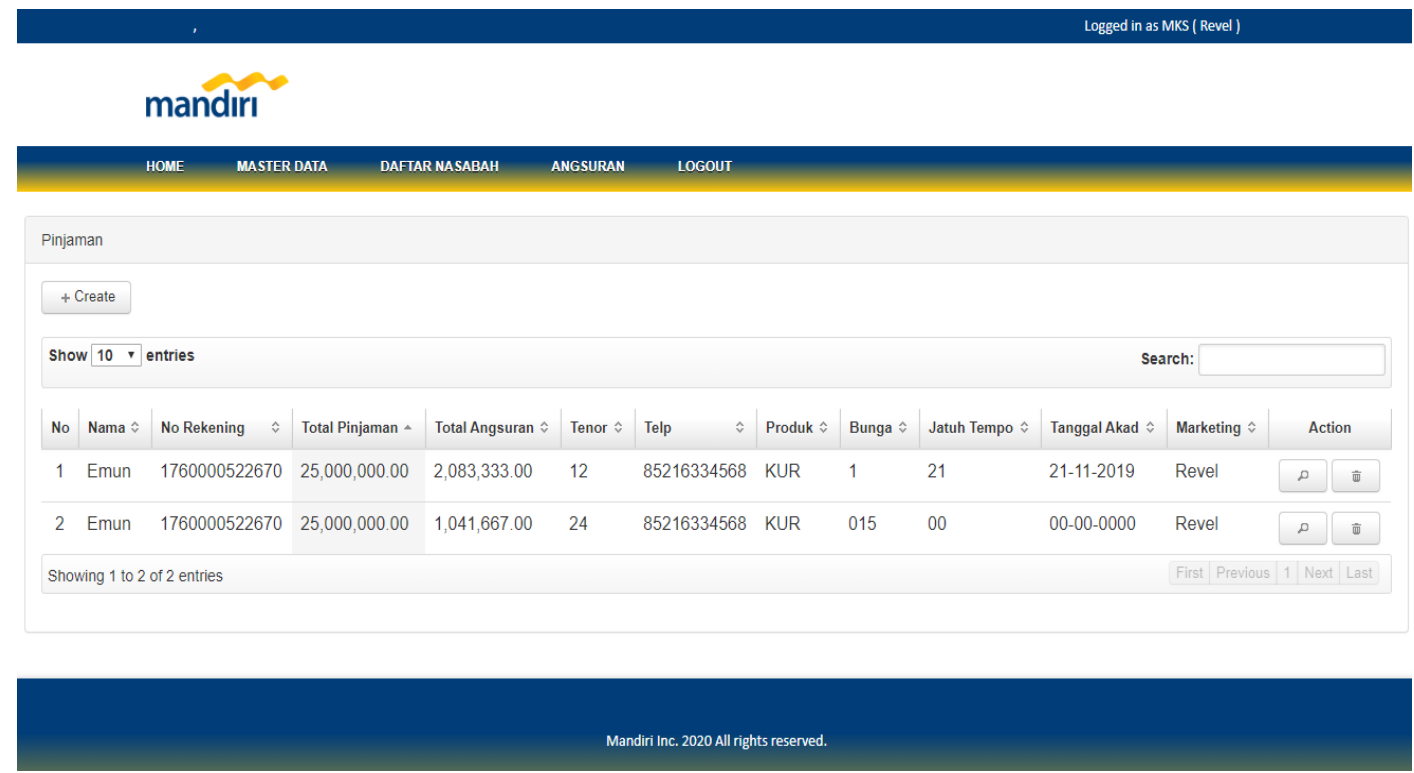

Gambar 4 halaman daftar nasabah

Gambar 4 adalah menampilkan daftar seluruh nasabah yang menjadi bagian dari bank mandiri unit cikupa niaga mas 2 yang akan dijadikan sebagai acuan dalam melakukan informasi angsuran.

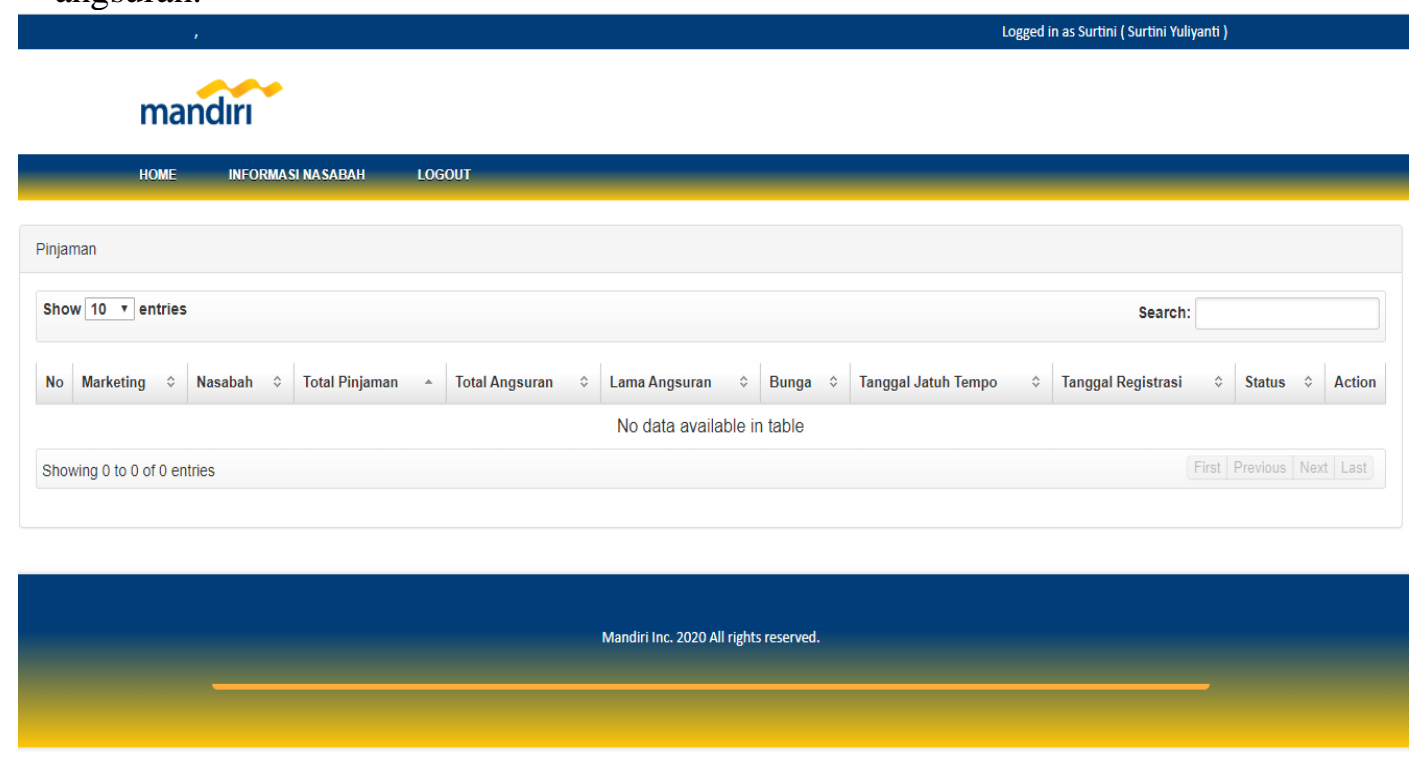

Gambar 5 halaman informasi angsuran

Gambar 5 adalah halaman untuk informasi angsuran nasabah dan akan menampilkan informasi angsuran nasabah sebagai acuan dalam menginformasikan tagihan nasabah yang harus dibayrakan.

\section{Kesimpulan}

Rancang Sistem informasi pembayaran angsuran nasabah memiliki manfaat untuk dapat membantu proses pengolahan data angsuran nasabah, data angsuran nasabah yang datang menjadi 
lebih akurat dan efektif dalam pelaporan pembayaran angsuran nasabah. Dengan sistem ini, dapat mempermudah petugas dalam mengolah informasi mengenai data nasabah yang sudah atau belum dibayar akan dapat diminimalisir. Untuk mendapatkan sistem yang dapat menyimpan data angsuran nasabah dengan rapih, mengurangi resiko kehilangan data-data nasabah, dan memepercepat petugas dalam pembuatan laporan mengenai data angsuran nasabah.

\section{Saran}

Saran dari peneliti dalam jurnal ini antara lain:

Diharapkan kedepannya sistem dapat diubah menjadi sistem yang lebih canggih lagi berbasis mobile android dari sistem sebelumnya. Dan perlu pengingkatan keakuratan pengguna dalam memproses pendataan angsuran nasabah guna menghindari resiko kehilangan data dan kesalahan.

\section{Daftar Pustaka}

[1] Rachman, A. 2018. Aplikasi Pembayaran dan Perizinan Santri Ponpes Assalafi Al Fithrah Surabaya Berbasis Web. Jurnal IPTEK, 22(1) 71-78

[2] Kurniawan, T. 2019. Rancang Bangun Aplikasi Pembayaran Cicilan Kredit Berbagai Toko Menggunakan Dompet Digital OVO. Jurnal SITECH, 2(1) 95-102

[3] Alfeno, A., Saptono, A., \& Pamungkas, A, B. 2018. Perancangan Antar Muka Aplikasi Monitoring Pembayaran Angsuran Kendaraan Bermotor Berbasis Android Pada PT Bentara Sinergies Multifinance. Jurnal Maklumatika, 5(1), 88-97

[4] Musyarrofah, S., Ashari, M., \& Fadli, S. 2019. Rancangan Sistem Informasi Konversi Mata Kuliah Mahasiswa Pindahan dan Lanjutan (Studi Kasus di STMIK Lombok). Jurnal JISA, 2(1), $18-2$ 